\title{
Nonreward confinement duration: The complement of reward magnitude'
}

\author{
E. J. CAPALDI AND HUGH B. POYNOR \\ UNIVERSITY OF TEXAS
}

\begin{abstract}
Abstraet
Forty-eight rats were trained in the runway for 10 trials each day for 18 days under a 50\% partial reinforcement schedule, confinement duration on the nonreinforced trials being either $10 \mathrm{sec}$. or $50 \mathrm{sec}$. Half of each group was extinguished under 10-sec. confinement $(10-10,50-10)$, half under 50-sec. $(50-50,10-50)$, there being seven days of extinction at six trials each day. Terminal extinction level was affected by confinement. A variety of hypotheses were applied to the results.
\end{abstract}

\section{Introduction}

Some studies report slower running the longer the rat is confined on nonrewarded trials (e.g., Stanley \& Rowe, 1954), whereas others report no difference due to confinement (e.g., Hulse, 1958). Recent studies in this laboratory (e.g., Bloom, 1963; Capaldi, in press) have uniformly yielded positive results. Indeed, in the Capaldi investigation when confinement durations were reversed performance shifted appropriately, as with changes in reward magnitude.

The confinement duration variable may have at least some bearing on all extinction hypotheses. For example, Stanley \& Rowe (1954) in the context of a contiguity theory suggest that with longer confinements more competing responses should occur. Thus it follows that early in extinction longer confinements should produce slower running. But later in extinction running should be independent of confinement. This follows because with repeated trials (nonrewards) the competing S-R tendencies should eventually possess the same (i.e., asymptotic) strength. Actually, it would seem that whatever one supposes about nonreward, more of it or different kinds of it should occur the bigger the nonreward.

\section{Method}

The Ss were 48 naive 90-day old rats. The runway, 82 in $\times 4$ in with 9-in high sides, was covered with hardware cloth. An 8-in floor treadle, when depressed by the rat whose front paws were always placed at its forward edge, started the first clock (.01 sec.). Clock 1 was stopped (start time) and Clock 2 started when S interrupted a photobeam 2 in beyond the treadle. Clock 2 was stopped (run time) and Clock 3 started when $\mathrm{S}$ broke the second photobeam located 52 in from the first. The last photobeam was $15-1 / 4$ in beyond the second photobeam (goal time) and $2-3 / 4$ in in front of a brass 2 by 4 by $1-1 / 2$ in food cup covered by a sliding lid which opened automatically when the last photobeam was broken. There were two identical food cups, one for reinforced trials (wet mash) and one for nonreinforced trials. A manually-lowered guillotine door, 14 in from the rear of the goal compartment, served to confine $S$ to the goal area.

The Ss were handled, tamed, and deprived for 14 days prior to acquisition. Acquisition occurred under a single alternating schedule of reward, 10 trials/day for 18 days. For half the Ss confinement on nonreinforced trials was 50 sec.; for the remaining half, $10 \mathrm{sec}$. Each group was randomly split in extinction, receiving either $50 \mathrm{sec}$. or $10 \mathrm{sec}$. extinction confinement (EC). There were seven days of extinction at six trials each day separated by a 20-sec.intertrial interval. Following the last trial of the day $S$ was returned to the home cage where $10 \mathrm{~min}$. later it was fed mash for $1 \mathrm{hr}$. The $\mathrm{S}$ was allowed $60 \mathrm{sec}$. to traverse each section of the runway.

\section{Results}

Mean log times along the total length of the alley are shown in Fig. 1 for the 50-sec. and 10-sec. confinement groups on each day of extinction. It is clear that Group E 50 ran slower than Group E 10 and, further, that by the end of training differences had stabilized suggesting that confinement duration influenced terminal extinction level. Note, too, that Group E 10 appeared to reach terminal level at a more rapid rate than Group E 50. Considering separate sections of the alley (data not shown), confinement failed to affect start times $(F<1)$ and was highly significant in the run $(\mathrm{F}=27.44, \mathrm{p}<.001)$ and goal $(\mathrm{F}=73.38, \mathrm{p}<.001)$ sections ( $d f=1 / 44$ in each case). A separate analysis over the

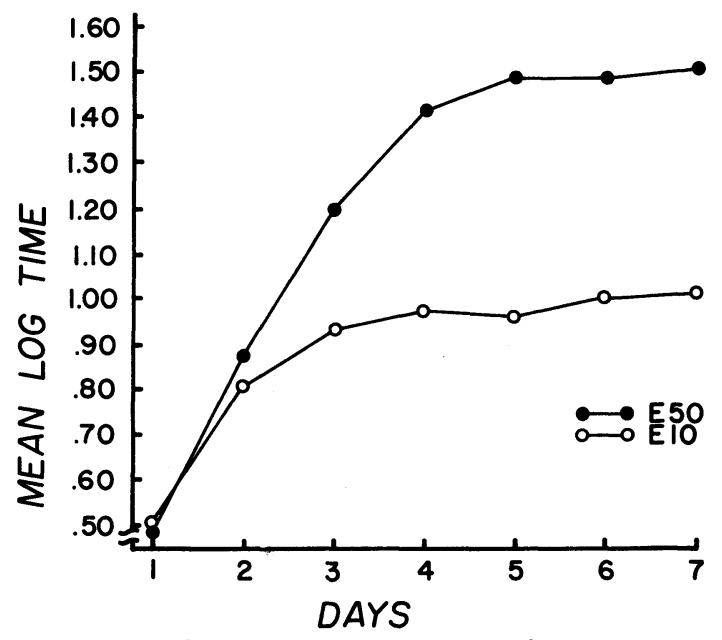

Fig. 1. Mean log running time for each of the groups on each day of extinction. 
first and last days of extinction showed that on Day 1 shifted groups (10-50 and 50-10) ran slower than nonshifted groups (10-10 and 50-50) $(\mathrm{F}=10.33, \mathrm{p}<.001$, $\mathrm{df}=1 / 44)$, but by the end of training the difference disappeared $(\mathrm{F}<1)$.

\section{Discussion}

It appears that (a) longer confinements produce slower running; (b) the effect increases toward to goal; (c) terminal running is affected by confinement, a finding not compatible with the "number of competing responses" hypothesis of Stanley \& Rowe (1954). Among presently feasible interpretations of confinement duration are (a) goal box removal is rewarding, and the shorter the confinement the less the delay of this reward and the faster the running; (b) different and possibly more intense (and therefore more effective) competing responses are learned under longer confinements; (c) nonreward is aversive and is increasingly more so, the longer the confinement. In the context of a frustration hypothesis (e.g., Spence, 1960) interpretations (b) and (c) would be highly similar. A fourth interpretation is offered below.

Assume that different magnitudes of reward and different confinement durations produce specific and discriminable stimulus aftereffects (Capaldi, in press) and that these influence performance through a stimulus intensity mechanism ( $V$ ). An advantage of this view is that all stimuli are treated alike, i.e., the view is general. Thus, a large reward evokes a more vigorous reaction for the same reason as does a loud noise (intensity). Spence (1956) suggested the feasibility of employing $\mathrm{V}$ in connection with rewarded stimuli $\left(r_{g}-s_{g}\right)$ - the notion is extended here to nonrewarded stimuli. Rewarded stimulus aftereffects tend to evoke forward locomotion, whereas nonrewarded stimulus aftereffects tend to evoke responses which compete with forward locomotion. Bigger rewards evoke more vigorous forward locomotion, and longer confinements evoke either different and/or stronger competing reactions. Note, the competing reactions are not learned, as assumed by contiguity theorists, but rather constitute the organism's unconditioned reaction to nonrewarded stimuli. This view seems more compatible with findings on the successive acquisition and extinction of reactions (e.g., North \& Morton, 1962) and perhaps with the finding that reversal of confinement duration produces appropriate and fairly rapid changes in performance (Capaldi, in press).

\section{References}

Bloom, J. M. The generalization of stimulus aftereffects in acquisition and extinction as a function of the duration of rewarded and nonrewarded goal box confinement. Unpublished doctoral dissertation. University of Texas, 1963.

Capaldi, E. J. Stimulus specificity: Nonreward. J. exp. Psychol., in press.

Hulse, S. H., Jr. Amount and percentage of reinforcement and duration of goal confinement in conditioning and extinction. J. exp. Psychol., 1958, 56, 48-57.

North, A. J., \& Morton, M. L. Successive acquisitions and extinctions of an instrumental response. J. comp. physiol. Psychol., 1962, 55, 974-977.

Spence, K. W. Behavior theory and conditioning. New Haven: Yale University Press, 1956.

Spence, K. W. Behavior theory and learning. Englewood Cliffs, N. J.: Prentice-Hall, 1960.

Stanley W. C., \& Rowe, M. I. Extinction by omission of food as a function of goal-box confinement. J. exp. Psychol., 1954, 48, 271-274.

Note

1. The research was supported in part by National Institute of Child Health and Human Development Research Grant HD 00949-02 to the first author. 